\title{
Association between exposure to suicide and suicidality outcomes in youth
}

\author{
Sonja A. Swanson ScM, Ian Colman PhD
}

See related commentary by Bohanna on page 861 and at www.cmaj.ca/lookup/doi/10.1503/cmaj.130678

Competing interests: None declared.

This article has been peer reviewed.

\section{Correspondence to:}

Ian Colman,

icolman@uottawa.ca

CMAJ 2013. DOI:10.1503

/cmaj.121377

\begin{abstract}
Background: Ecological studies support the hypothesis that suicide may be "contagious" (i.e., exposure to suicide may increase the risk of suicide and related outcomes). However, this association has not been adequately assessed in prospective studies. We sought to determine the association between exposure to suicide and suicidality outcomes in Canadian youth.
\end{abstract}

Methods: We used baseline information from the Canadian National Longitudinal Survey of Children and Youth between 1998/99 and 2006/07 with follow-up assessments 2 years later. We included all respondents aged 12-17 years in cycles 3-7 with reported measures of exposure to suicide.

Results: We included 8766 youth aged 12-13 years, 7802 aged $14-15$ years and 5496 aged 16-17 years. Exposure to a schoolmate's suicide was associated with ideation at baseline among respondents aged 12-13 years (odds ratio [OR] 5.06, 95\% confidence interval [Cl] $3.04-8.40$ ), $14-15$ years (OR $2.93,95 \%$ Cl $2.02-$
4.24) and 16-17 years (OR 2.23, 95\% Cl 1.433.48). Such exposure was associated with attempts among respondents aged 12-13 years (OR 4.57, 95\% Cl 2.39-8.71), 14-15 years (OR 3.99, 95\% Cl 2.46-6.45) and 16-17 years (OR $3.22,95 \% \mathrm{Cl} 1.62-6.41$ ). Personally knowing someone who died by suicide was associated with suicidality outcomes for all age groups. We also assessed 2-year outcomes among respondents aged 12-15 years: a schoolmate's suicide predicted suicide attempts among participants aged 12-13 years (OR 3.07, 95\% Cl 1.05-8.96) and 14-15 years (OR 2.72, 95\% Cl 1.47-5.04). Among those who reported a schoolmate's suicide, personally knowing the decedent did not alter the risk of suicidality.

Interpretation: We found that exposure to suicide predicts suicide ideation and attempts. Our results support school-wide interventions over current targeted interventions, particularly over strategies that target interventions toward children closest to the decedent.
$\mathrm{S}$ uicidal thoughts and behaviours are prevalent $^{1-3}$ and severe ${ }^{4-7}$ among adolescents. One hypothesized cause of suicidality is "suicide contagion" (i.e., exposure to suicide or related behaviours influences others to contemplate, attempt or die by suicide). ${ }^{8}$ Ecological studies support this theory: suicide and suspected suicide rates increase following a highly publicized suicide..$^{9-11}$ However, such studies are prone to ecological fallacy and do not allow for detailed understanding of who may be most vulnerable.

Adolescents may be particularly susceptible to this contagion effect. More than $13 \%$ of adolescent suicides are potentially explained by clustering; ${ }^{12-14}$ clustering may explain an even larger proportion of suicide attempts. ${ }^{15,16}$ Many local, ${ }^{17,18}$ national ${ }^{8,19}$ and international ${ }^{20}$ institutions recommend school- or community-level postvention strategies in the aftermath of a suicide to help prevent further suicides and suicidality. These postvention strategies typically focus on a short interval following the death (e.g., months) with services targeted toward the most at-risk individuals (e.g., those with depression). ${ }^{19}$

In this study, we assessed the association between exposure to suicide and suicidal thoughts and attempts among youth, using both cross-sectional and prospective (2-yr follow-up) analyses in a population-based cohort of Canadian youth.

\section{Methods}

\section{Study design}

The National Longitudinal Survey of Children and Youth is a population-based nationally representative cohort study involving 16903 Cana- 
dian children that began in 1994/95 when the participants were aged $0-11$ years; ${ }^{21}$ biennial data collection continued through 2008/09. Details about the cohort, including study design and response rates (mostly above $80 \%$ for each wave), are described elsewhere. ${ }^{21,22}$ In the current study, we included measures primarily from agespecific questionnaires given to the respondents and to the person most knowledgeable about the respondent (typically the biological mother). We focused on youth who were 12-17 years of age in the third (1998/99) through seventh (2006/07) cycles, because these cycles included suicidality measurements and allowed 2 years of follow-up. Age (not calendar year) was the primary timescale. We stratified by 2 -year age groups; this maintained independent observations and allowed for possible effect modification by age group. Our study includes 8766 observations among youth aged 12-13 years, 7802 among those aged 14-15 years and 5496 among those aged 16-17 years.

\section{Measures}

Respondents were asked whether anyone in their school had died by suicide (schoolmate's suicide) and whether they personally knew anyone who had died by suicide (personally known suicide). Respondents could answer: "yes" (past year); "yes" (> 1 yr ago); "no"; or "I don't know." We excluded the "I don't know" responses from the primary analyses.

Respondents were asked if they had seriously considered attempting suicide in the past year. If they answered yes, they were asked to report the number of suicide attempts in the past year, which we dichotomized as 0 or $\geq 1$. Of note, we used a higher threshold for assessing ideation (i.e., "seriously considering") than has been used in previous studies. ${ }^{1,23}$

Respondents aged 12-15 years were asked items originally from the Ontario Child Health Study; at ages 10-11, these items were answered by the person most knowledgeable about the respondent. ${ }^{24}$ The Ontario Child Health Study consists of symptom checklist scales based on the Diagnostic and Statistical Manual of Mental Disorders, third edition (DSM-III) and DSM-III-R (revised), with 1 subscale that assessed the occurrence and severity of symptoms of depression and anxiety in the past week. ${ }^{24,25}$ The psychometric properties of the Ontario Child Health Study have been extensively documented. ${ }^{24-26} \mathrm{We}$ dichotomized scores around the top decile by age group, which is compatible with the prevalence of depression or anxiety in previous surveys. ${ }^{27}$

Respondents aged 12-15 years were asked about drug and alcohol use, including how fre- quently they had been drunk in the past year. Because of changes in response options over survey cycles, we dichotomized this behaviour as those who reported being intoxicated at least monthly versus less than monthly. Participants were asked whether they had used marijuana, hallucinogens, glue or inhalants, prescription drugs (without a prescription) and other drugs during the past year.

Socioeconomic status was measured using a ratio of household income to the low-income cut-off score. This score takes into account an individual's income relative to the community in which they live and the size of their family. ${ }^{28} \mathrm{We}$ dichotomized this score to indicate whether household income was at or above the lowincome cut-off (e.g., ratio $\geq 1$ )

Respondents completed an abbreviated version of the Social Provisions Scale, a well-validated measure of perceived social support. ${ }^{29-31}$ We considered scores below the sample median to indicate low social support.

The person most knowledgeable about the respondent reported about stressful life events; prior research suggests that parent and child reports of severe stressful life events have substantial concordance. ${ }^{32}$ Stressful life events included the death of a parent or family member; divorce or separation; household move; stay in a hospital; stay in a foster home; other separation from parents; illness or injury of child or family member; abuse or fear of abuse; change in household members; alcoholism or mental health disorder in the family; conflict between parents; problems at school; death of a pet; or other traumatic event. Respondents were grouped by whether any stressful life event was reported. We considered past events to be potential effect modifiers, but not confounding variables, because we could not meaningfully distinguish whether a stressful life event referenced the same event as the exposure (e.g., suicide death of family member or a peer's suicide reported as "other").

\section{Statistical analyses}

We weighted all estimates to adjust for unequal selection probabilities, cluster sampling and attrition, with bootstrapped standard errors; ${ }^{21,22}$ weights were further calibrated because of the use of multiple survey cycles to construct age-based cohorts.

For our primary analyses, we estimated crude and adjusted odds ratios (ORs) and their 95\% confidence intervals (CIs) using logistic regression. Fully adjusted models included sex, socioeconomic status, previous (i.e., reported in the previous cycle 2 years before exposure) depression or anxiety, previous monthly drinking episodes and previous drug use. Given the format of the ques- 
tions (e.g., "past year" exposure), we adjusted for confounding variables from the previous cycle to avoid potentially conditioning on symptoms or

Table 1: Weighted characteristics of the respondents, by age

\begin{tabular}{|lccc|}
\hline & \multicolumn{3}{c}{ Age, yr, \% $\pm \mathrm{SE}^{*}$} \\
\cline { 2 - 4 } Characteristic & $12-13$ & $14-15$ & $16-17$ \\
\hline No. of participants, unweighted & 8766 & 7802 & 5496 \\
\hline Female & $49.8 \pm 0.4$ & $49.7 \pm 0.4$ & $51.0 \pm 0.4$ \\
\hline Male & $50.2 \pm 0.4$ & $50.3 \pm 0.4$ & $49.0 \pm 0.4$
\end{tabular}

\section{Current survey cycle}

Socioeconomic status

\begin{tabular}{|lrrr}
\hline Below low-income cut-off & $13.4 \pm 0.6$ & $12.0 \pm 0.7$ & $11.0 \pm 0.7$ \\
\hline At or above low-income cut-off & $86.6 \pm 0.6$ & $88.0 \pm 0.7$ & $89.0 \pm 0.7$ \\
\hline Suicide by a schoolmate & & & \\
\hline In past yr & $3.6 \pm 0.3$ & $9.4 \pm 0.6$ & $9.3 \pm 0.6$ \\
\hline$>1$ yr ago & $3.6 \pm 0.3$ & $9.7 \pm 0.5$ & $14.8 \pm 0.8$ \\
\hline No suicides & $51.0 \pm 0.8$ & $30.6 \pm 0.8$ & $36.4 \pm 1.0$ \\
\hline Don't know & $41.8 \pm 0.8$ & $50.3 \pm 0.9$ & $39.5 \pm 1.0$ \\
\hline
\end{tabular}

Suicide by someone they knew personally

\begin{tabular}{|lrrr|}
\hline In past yr & $3.7 \pm 0.3$ & $5.6 \pm 0.4$ & $6.9 \pm 0.5$ \\
\hline$>1$ yr ago & $6.0 \pm 0.4$ & $8.2 \pm 0.5$ & $13.2 \pm 0.7$ \\
\hline No suicides & $79.3 \pm 0.7$ & $75.8 \pm 0.7$ & $72.9 \pm 1.0$ \\
\hline Don't know & $11.0 \pm 0.5$ & $10.4 \pm 0.5$ & $7.0 \pm 0.5$ \\
\hline Suicide ideation & & & \\
\hline Yes & $5.8 \pm 0.4$ & $9.7 \pm 0.5$ & $9.8 \pm 0.6$ \\
\hline No & $94.2 \pm 0.4$ & $90.3 \pm 0.5$ & $90.2 \pm 0.6$ \\
\hline Suicide attempt & & & \\
\hline Yes & $2.9 \pm 0.3$ & $4.7 \pm 0.3$ & $4.5 \pm 0.4$ \\
\hline No & $97.1 \pm 0.3$ & $95.3 \pm 0.3$ & $95.5 \pm 0.4$ \\
\hline
\end{tabular}

\section{Previous survey cycle}

Stressful life event $†$

\begin{tabular}{|c|c|c|c|}
\hline$\geq 1$ event & $34.8 \pm 0.8$ & $35.8 \pm 0.9$ & $32.8 \pm 1.0$ \\
\hline 0 events & $65.2 \pm 0.8$ & $64.2 \pm 0.9$ & $67.2 \pm 1.0$ \\
\hline \multicolumn{4}{|c|}{ Drinking to intoxication, $\neq$} \\
\hline$\geq 1$ time $/ \mathrm{mo}$ & NA & $0.6 \pm 0.2$ & $9.1 \pm 0.7$ \\
\hline$<1$ time/mo & NA & $99.4 \pm 0.2$ & $90.9 \pm 0.7$ \\
\hline \multicolumn{4}{|l|}{ Drug use } \\
\hline Yes & NA & $5.2 \pm 0.4$ & $22.5 \pm 0.9$ \\
\hline No & NA & $94.8 \pm 0.4$ & $77.5 \pm 0.9$ \\
\hline \multicolumn{4}{|c|}{ Suicide attempt‡§ } \\
\hline Yes & NA & $2.9 \pm 0.3$ & $4.7 \pm 0.4$ \\
\hline No & NA & $97.1 \pm 0.3$ & $95.3 \pm 0.4$ \\
\hline
\end{tabular}

Note: NA = not applicable, SE = standard error.

*Unless otherwise indicated.

tStressful life events reported in the previous survey cycle 2 yr earlier (e.g., ages 10-11 yr for those aged 12-13 yr at baseline).

‡Reported at previous assessment $2 \mathrm{yr}$ earlier (e.g., ages 12-13 yr for those aged 14-15 yr at baseline). These measures were not assessed prior to age 12; thus, no data are available for those aged $12-13 \mathrm{yr}$ at baseline.

§Previous suicide attempts were only assessed in the subset of respondents with baseline information from cycles 4-7 (not 3-7) because of availability of the assessment. behaviours occurring after exposure to suicide.

We assessed whether personally knowing a peer decedent (reported a schoolmate's suicide and reported a suicide by someone they knew personally) increased the risk of suicidality outcomes relative to a lesser-known peer decedent (reported a schoolmate's suicide only), using models fit among the subpopulation who reported a schoolmate's suicide. These analyses assumed that the decedent was the same person for both exposures. Finally, we assessed whether previous (reported at ages 12-13 yr) stressful life events, social support, depression or anxiety, or ideation and/or attempts modified the effects of suicide exposure at ages 14-15 on suicidality outcomes 2 years later (ages 16-17).

Of the eligible youth, $41.8 \%(12-13 \mathrm{yr})$, $50.3 \%(14-15 \mathrm{yr})$ and $39.5 \%$ (16-17 yr) for the schoolmate's suicide variable and $11.0 \%$ (12$13 \mathrm{yr}$ ), $10.4 \%$ (14-15 yr) and 7.0\% (16-17 yr) for the personally known suicide variable of each age group responded "I don't know." Because of these notable proportions, we performed sensitivity analyses in which we classified such responses as nonendorsement instead of missing, assuming many of those who responded "I don't know" were actually unexposed or unaffected.

\section{Results}

\section{Exposure to suicide}

The prevalence of exposure to a schoolmate's suicide and personally knowing someone who died by suicide increased with age (Table 1). By ages 16-17 years, $24.1 \%$ of respondents reported a schoolmate's suicide, and $20.1 \%$ reported personally knowing someone who died by suicide. These are conservative estimates because some individuals who responded "I don't know" may have been exposed.

\section{Cross-sectional analysis}

In our cross-sectional analysis, exposure to a schoolmate's suicide was associated with suicidality (Table 2). Among respondents aged 12-13 years, $15.3 \%$ of those exposed in the past year reported ideation, compared with $3.4 \%$ of those unexposed; a similar difference was seen in attempts $(7.5 \%$ v. $1.7 \%)$. Among respondents aged 14-15 years, exposure to a schoolmate's suicide was associated with increased risk of ideation (14.2\% v. $5.3 \%)$ and attempts (8.6\% v. $2.3 \%)$. A similar pattern was seen among those aged 16-17 years for ideation (15.1\% v. $7.4 \%)$ and attempts $(8.1 \%$ v. $2.7 \%)$. Respondents who reported that exposure occurred over a year ago also had higher risks compared with those who were not exposed. Fully adjusted ORs for these 
associations ranged in magnitude from 1.83 to 6.46 , and sensitivity analyses slightly attenuated the results (Appendix 1, available at www.cmaj.ca /lookup/suppl/doi:10.1503/cmaj.121377/-/DC1).

Personally knowing someone who died of suicide was associated with suicidality in our cross-sectional analysis (Table 3). Among respondents aged $12-13$ years, $13.7 \%$ of those exposed in the past year reported ideation compared with $4.6 \%$ of those who were not exposed; $5.6 \%$ and $2.3 \%$ of these respondents reported attempts, respectively. This pattern was consistent among respondents aged 14-15 years for ideation (18.4\% v. $7.6 \%)$ and attempts $(12.5 \%$ v. $3.6 \%)$, and among respondents aged $16-17$ years for ideation (14.0\% v. $8.1 \%)$ and attempts $(8.4 \%$ v. $3.2 \%)$. Respondents who reported exposure that occurred over a year ago also had higher risks than those who were not exposed. The fully adjusted ORs ranged from 1.75 to 4.02 , and the sensitivity analyses produced slightly attenuated results (Appendix 2, available at www.cmaj.ca /lookup/suppl/doi:10.1503/cmaj.121377/-/DC1).

\section{Prospective analysis}

Associations between exposure to suicide and suicidality outcomes 2 years later are presented in Table 4. Among participants aged 12-13 years, a schoolmate's suicide was associated with suicide attempts 2 years later (OR 3.07, 95\% CI 1.058.96). Among those aged 14-15 years, exposure to a schoolmate's suicide was associated with

Table 2: Cross-sectional association between suicide of a schoolmate and suicidality outcomes in youth

\begin{tabular}{|c|c|c|c|}
\hline \multirow[b]{2}{*}{ Group; outcome; suicide exposure } & \multicolumn{3}{|c|}{ OR $(95 \% \mathrm{Cl})$} \\
\hline & Unadjusted & Partially adjusted* & Fully adjusted* \\
\hline \multicolumn{4}{|l|}{ Ages 12-13 yr } \\
\hline \multicolumn{4}{|l|}{ Ideation } \\
\hline Exposure in past yr & $5.06(3.04-8.40)$ & $5.09(3.03-8.57)$ & $6.46(3.56-11.72)$ \\
\hline Exposure $>1 \mathrm{yr}$ ago & $4.57(2.87-7.29)$ & $4.58(2.87-7.32)$ & $4.08(2.43-6.86)$ \\
\hline No exposure & Ref & Ref & Ref \\
\hline \multicolumn{4}{|l|}{ Attempt } \\
\hline Exposure in past yr & $4.57(2.39-8.71)$ & $4.68(2.37-9.24)$ & $5.93(2.67-13.20)$ \\
\hline Exposure $>1 \mathrm{yr}$ ago & $5.80(3.07-10.97)$ & $5.65(2.98-10.70)$ & $5.05(2.50-10.19)$ \\
\hline No exposure & Ref & Ref & Ref \\
\hline \multicolumn{4}{|l|}{ Ages 14-15 yr } \\
\hline \multicolumn{4}{|l|}{ Ideation } \\
\hline Exposure in past yr & $2.93(2.02-4.24)$ & $2.78(1.91-4.04)$ & $2.85(1.85-4.41)$ \\
\hline Exposure $>1 \mathrm{yr}$ ago & $2.89(2.01-4.15)$ & $2.66(1.84-3.84)$ & $2.35(1.55-3.54)$ \\
\hline No exposure & Ref & Ref & Ref \\
\hline \multicolumn{4}{|l|}{ Attempt } \\
\hline Exposure in past yr & $3.99(2.46-6.45)$ & $3.62(2.21-5.94)$ & $3.41(1.93-6.04)$ \\
\hline Exposure $>1 \mathrm{yr}$ ago & $3.88(2.40-6.27)$ & $3.38(2.07-5.52)$ & $2.98(1.70-5.22)$ \\
\hline No exposure & Ref & Ref & Ref \\
\hline \multicolumn{4}{|l|}{ Ages 16-17 yr } \\
\hline \multicolumn{4}{|l|}{ Ideation } \\
\hline Exposure in past yr & $2.23(1.43-3.48)$ & $2.21(1.40-3.47)$ & $1.83(1.04-3.21)$ \\
\hline Exposure > 1 yr ago & $1.86(1.18-2.93)$ & $1.79(1.13-2.84)$ & $1.97(1.14-3.41)$ \\
\hline No exposure & Ref & Ref & Ref \\
\hline \multicolumn{4}{|l|}{ Attempt } \\
\hline Exposure in past yr & $3.22(1.62-6.41)$ & $3.13(1.53-6.43)$ & $3.26(1.35-7.89)$ \\
\hline Exposure $>1 \mathrm{yr}$ ago & $2.33(1.17-4.61)$ & $2.18(1.08-4.40)$ & $2.04(0.84-4.96)$ \\
\hline No exposure & Ref & Ref & Ref \\
\hline \multicolumn{4}{|c|}{$\begin{array}{l}\text { Note: } \mathrm{Cl}=\text { confidence interval, } \mathrm{OR}=\text { odds ratio, ref }=\text { reference. } \\
\text { *Partially adjusted models account for sex and socioeconomic status. For ages } 14-15 \mathrm{yr} \text { and } 16-17 \mathrm{yr} \text {, the fully adjusted models } \\
\text { account for sex, socioeconomic status, previous depression or anxiety, previous monthly drinking episodes and previous drug } \\
\text { use (as reported in the previous survey cycle). For ages } 12-13 \mathrm{yr} \text {, the fully adjusted models account for sex, socioeconomic status } \\
\text { and previous depression or anxiety. }\end{array}$} \\
\hline
\end{tabular}


both ideation (OR 1.65, 95\% CI 1.06-2.55) and attempts (OR 2.72, 95\% CI 1.47-5.04); personally knowing someone who died by suicide was also associated with attempts (OR 2.13, 95\% CI $1.10-4.13)$. In the fully adjusted models, schoolmate's suicide remained predictive of suicidality among those aged 14-15 years, although the ORs were attenuated in the sensitivity analyses (Appendix 3, available at www.cmaj.ca/lookup /suppl/doi:10.1503/cmaj.121377/-/DC1).

\section{Proximity to a schoolmate's suicide}

Among those who reported a schoolmate's suicide, personally knowing the decedent was not significantly associated with suicidality out- comes in 8 of the 10 models assessed (i.e., across the 3 age groups and 2 suicidality outcomes, cross-sectionally and prospectively; all $p>0.05$ ). Results for 1 model were suppressed because of data confidentiality restrictions; the only significant association was among participants aged 1617 years. Those who reported a schoolmate's suicide and personally knowing someone who died of suicide had marginally greater risk of baseline suicide attempts than those who reported a schoolmate's suicide alone $(p=0.046)$.

\section{Potential effect modification}

The effects of suicide exposure on suicidality outcomes were not modified by previous social

\begin{tabular}{|c|c|c|c|}
\hline \multirow[b]{2}{*}{ Group; outcome; suicide exposure } & \multicolumn{3}{|c|}{ OR $(95 \% \mathrm{Cl})$} \\
\hline & Unadjusted & Partially adjusted* & Fully adjusted* \\
\hline \multicolumn{4}{|l|}{ Ages 12-13 yr } \\
\hline \multicolumn{4}{|l|}{ Ideation } \\
\hline Exposure in past yr & $3.28(1.98-5.43)$ & $3.35(2.00-5.62)$ & $4.02(2.22-7.27)$ \\
\hline Exposure $>1$ yr ago & $1.87(1.26-2.76)$ & $1.91(1.29-2.83)$ & $1.75(1.10-2.79)$ \\
\hline No exposure & Ref & Ref & Ref \\
\hline \multicolumn{4}{|l|}{ Attempt } \\
\hline Exposure in past yr & $2.57(1.31-5.04)$ & $2.53(1.26-5.07)$ & $3.20(1.48-6.90)$ \\
\hline Exposure > 1 yr ago & $2.77(1.66-4.62)$ & $2.80(1.68-4.68)$ & $2.74(1.48-5.08)$ \\
\hline No exposure & Ref & Ref & Ref \\
\hline \multicolumn{4}{|l|}{ Ages 14-15 yr } \\
\hline \multicolumn{4}{|l|}{ Ideation } \\
\hline Exposure in past yr & $2.74(1.86-4.04)$ & $2.56(1.73-3.77)$ & $2.84(1.79-4.49)$ \\
\hline Exposure $>1 \mathrm{yr}$ ago & $2.42(1.77-3.30)$ & $2.21(1.61-3.03)$ & $2.28(1.57-3.31)$ \\
\hline No exposure & Ref & Ref & Ref \\
\hline \multicolumn{4}{|l|}{ Attempt } \\
\hline Exposure in past yr & $3.82(2.43-6.01)$ & $3.47(2.19-5.50)$ & $3.59(2.06-6.26)$ \\
\hline Exposure $>1$ yr ago & $2.51(1.69-3.73)$ & $2.23(1.48-3.37)$ & $2.07(1.27-3.39)$ \\
\hline No exposure & Ref & Ref & Ref \\
\hline \multicolumn{4}{|l|}{ Ages 16-17 yr } \\
\hline \multicolumn{4}{|l|}{ Ideation } \\
\hline Exposure in past yr & $1.86(1.20-2.88)$ & $1.86(1.20-2.90)$ & $1.85(1.12-3.05)$ \\
\hline Exposure $>1$ yr ago & $2.11(1.51-2.96)$ & $1.92(1.36-2.70)$ & $1.80(1.18-2.76)$ \\
\hline No exposure & Ref & Ref & Ref \\
\hline \multicolumn{4}{|l|}{ Attempt } \\
\hline Exposure in past yr & $2.80(1.57-4.97)$ & $2.83(1.57-5.11)$ & $3.14(1.53-6.44)$ \\
\hline Exposure $>1 \mathrm{yr}$ ago & $2.68(1.69-4.24)$ & $2.30(1.41-3.74)$ & $2.25(1.19-4.25)$ \\
\hline No exposure & Ref & Ref & Ref \\
\hline $\begin{array}{l}\text { Note: } \mathrm{Cl}=\text { confidence interval, } \mathrm{OR}=\text { odds } \mathrm{r} \\
\text { *Partially adjusted models account for sex } \\
\text { account for sex, socioeconomic status, prev } \\
\text { use (as reported in the previous survey cycl } \\
\text { and previous depression or anxiety. }\end{array}$ & $\begin{array}{l}\text { reference. } \\
\text { conomic status. For a } \\
\text { ssion or anxiety, prev } \\
\text { s } 12-13 \mathrm{yr} \text {, the fully a }\end{array}$ & $\begin{array}{l}4-15 \mathrm{yr} \text { and } 16-17 \mathrm{yr} \text {, th } \\
\text { monthly drinking episo }\end{array}$ & $\begin{array}{l}\text { ully adjusted models } \\
\text { and previous drug } \\
\text { socioeconomic statu }\end{array}$ \\
\hline
\end{tabular}


support, depression or anxiety, ideation, or attempts (all $p>0.05$ ). There was a significant interaction between a previous stressful life event and schoolmate's suicide in predicting ideation $(p=0.02)$ and attempts 2 years later $(p=0.03)$; exposure was predictive of outcomes for those with previous stressful life events, but there was no association among participants with no previous stressful life event. A similar, but not significant, trend was seen for previous stressful life events modifying the association between personally knowing someone who died by suicide and ideation $(p=0.08)$ and attempts $(p=0.1)$.

\section{Interpretation}

We found that exposure to suicide predicts suicidality. This was true for all age groups, although exposure to suicide increased the risk most dramatically in the youngest age group, when baseline suicidality was relatively low. Both types of suicide exposures assessed (schoolmate's suicide and personally knowing someone who died by suicide) predicted suicidality, although the death of a schoolmate by suicide generally had a stronger effect. Exposure was consistently associated with attempts (the more serious of the outcomes considered), and to a lesser degree ideation; some of these associations were still significant 2 years later.
Exposure to suicide was not uncommon: in the oldest age group (16-17 yr), 9\% of respondents reported that a schoolmate had died by suicide in the past year; an additional 15\% reported that a schoolmate had died by suicide more than a year earlier. These prevalences are supported by national death statistics: assuming an average school size of 1000 students, an expected $9 \%$ of older adolescents would be exposed each year, and more than $25 \%$ of these adolescents would have been exposed at some point in their youth. ${ }^{33}$ Given that such exposure is not rare, and appears to be strongly related to suicidality outcomes, further understanding of this association has the potential to help in the prevention of a substantial proportion of adolescent suicidal behaviours.

Current postvention strategies target the "ensuing months" following a suicide, ${ }^{19}$ despite limited longitudinal studies empirically validating this risk window. One such study suggested that exposure to suicide had no long-term impact on suicide attempts 3 years later; however, this study compared friends of the decedent to community controls and may have been underpowered. ${ }^{34}$ Our prospective analyses suggest that suicide exposure still has some measurable effects 2 or more years later.

Broadly, suicide death of a schoolmate was a stronger predictor of suicidality outcomes than

Table 4: Prospective association between exposure to suicide and suicidality outcomes 2 years later

\begin{tabular}{|c|c|c|c|}
\hline \multirow[b]{2}{*}{ Group; outcome; suicide exposure } & \multicolumn{3}{|c|}{ OR $(95 \% \mathrm{Cl})$} \\
\hline & Unadjusted & Partially adjusted* & Fully adjusted* \\
\hline \multicolumn{4}{|c|}{ Exposed to suicide of a schoolmate } \\
\hline \multicolumn{4}{|c|}{ Ages $12-13 \mathrm{yr}$} \\
\hline Ideation & $1.61(0.71-3.67)$ & $1.77(0.78-4.04)$ & $0.93(0.32-2.72)$ \\
\hline Attempt & $3.07(1.05-8.96)$ & $3.52(1.20-10.33)$ & $1.46(0.28-7.56)$ \\
\hline \multicolumn{4}{|l|}{ Ages $14-15 \mathrm{yr}$} \\
\hline Ideation & $1.65(1.06-2.55)$ & $1.65(1.06-2.55)$ & $1.82(1.13-2.94)$ \\
\hline Attempt & $2.72(1.47-5.04)$ & $2.62(1.41-4.86)$ & $2.68(1.34-5.34)$ \\
\hline \multicolumn{4}{|c|}{$\begin{array}{l}\text { Exposed to suicide of someone } \\
\text { personally known by the respondent }\end{array}$} \\
\hline \multicolumn{4}{|l|}{ Ages $12-13 \mathrm{yr}$} \\
\hline Ideation & $1.30(0.65-2.60)$ & $1.39(0.69-2.78)$ & $1.41(0.67-2.97)$ \\
\hline Attempt & $1.55(0.63-3.81)$ & $1.67(0.66-4.18)$ & $1.85(0.64-5.35)$ \\
\hline \multicolumn{4}{|l|}{ Ages $14-15 \mathrm{yr}$} \\
\hline Ideation & $1.56(0.97-2.49)$ & $1.50(0.95-2.38)$ & $1.46(0.86-2.48)$ \\
\hline Attempt & $2.13(1.10-4.13)$ & $1.98(1.03-3.81)$ & $1.83(0.82-4.09)$ \\
\hline \multicolumn{4}{|c|}{$\begin{array}{l}\text { Note: } \mathrm{Cl}=\text { confidence interval, } \mathrm{OR}=\text { odds ratio. } \\
\text { *Partially adjusted models account for sex and socioeconomic status. For ages } 14-15 \mathrm{yr} \text { and } 16-17 \mathrm{yr} \text {, the fully adjusted models } \\
\text { account for sex, socioeconomic status, previous depression or anxiety, previous monthly drinking episodes and previous drug } \\
\text { use (as reported in the previous survey cycle). For ages } 12-13 \mathrm{yr} \text {, fully adjusted models account for sex, socioeconomic status and } \\
\text { previous depression or anxiety. }\end{array}$} \\
\hline
\end{tabular}


suicide by someone personally known, perhaps because the death of a peer resonates with youth more than the death of a close adult. This finding is particularly relevant for addressing homophily (i.e., confounding due to relationships based on shared risk factors). Unmeasured or residual confounding is likely present when exposure involved knowing the decedent, because friendships may be formed around shared suicidality risk factors, and shared genetic risk factors for suicide may explain increased risk of suicidality when the decedent and respondent were biologically related..$^{35,36}$ However, such confounders are unlikely to influence correlations between a schoolmate's suicide and suicidality, because the exposure assessment could be interpreted as attendance at the same school as the decedent and not necessarily as friendship or other forms of proximity with overlapping risk factors.

Among those who reported a schoolmate's suicide, personally knowing the decedent did not predict suicidality outcomes. Thus, perhaps any exposure to a peer's suicide is relevant, regardless of the proximity to the decedent. Although some research has suggested that close friends are more strongly affected by a suicide death, ${ }^{37}$ our results align with Brent and colleagues' findings: the closest friends of a suicide victim do not have an increased risk of suicidality compared with acquaintances. ${ }^{38}$ Thus, it may be best for postvention strategies to include all students rather than target close friends. Our results similarly dissuade targeting "high-risk" groups; of exception, youth who have experienced a stressful life event may be more affected by suicide exposure, a result supported by a previous study assessing the risk of posttraumatic stress disorder in witnesses of suicide. ${ }^{39}$

\section{Strengths and limitations}

Our study has several strengths. First, we used a large, nationally representative prospective cohort to examine the association between exposure to suicide and suicidality outcomes. Second, we included 2 important types of suicide exposure (schoolmate's suicide and personally knowing someone who died by suicide) along with several relevant covariates.

Nonetheless, the limitations warrant consideration. Unmeasured confounding is a concern; however, given the strong associations observed between exposure and outcome among participants aged 12-13 years, among whom most risk factors would be rare, such confounding is unlikely to alter the conclusions. The exposure variables were assessed via 2 self-reported questions, and we cannot more specifically determine the relationship between the respondent and the deceased. The degree of proximity may warrant further research, in particular because among those who reported a schoolmate's suicide, personally knowing the decedent was not predictive of suicidality outcomes; moreover, potential confounding variables may differ depending on the type of relationship. No information was provided on postvention programs or media exposure following a suicide death in the school or community. Thus, we cannot assess whether these may have mediated any of the effects, and we can only surmise that there is an average overall association irrespective of how a suicide event was handled in these schools or communities.

\section{Conclusion}

Suicidality is of utmost public health concern, both as a predictor of suicide and because of its own burden on individuals ${ }^{4-7}$ and society. ${ }^{5-7}$ Thus, it is critical to identify risk factors and implement evidence-based prevention and intervention suicide policies. We found that exposure to suicide may be a strong predictor of suicidality. Our findings support school- or community-wide interventions over strategies targeting those who personally knew the decedent, suggests that allocating resources following an event may be especially important during earlier adolescence, and implies that schools and communities should be aware of an increased risk for at least 2 years following a suicide event.

\section{References}

1. Husky MM, Olfson M, He JP, et al. Twelve-month suicidal symptoms and use of services among adolescents: results from the National Comorbidity Survey. Psychiatr Serv 2012;63:989-96.

2. West BA, Swahn MH, McCarty F. Children at risk for suicide attempt and attempt-related injuries: findings from the 2007 Youth Risk Behavior Survey. West J Emerg Med 2010;11:257-63.

3. Trends in the prevalence of suicide-related behaviors: National YRBS 1991-2009. Atlanta (GA): Centers for Disease Control and Prevention; 2011. Available: www.cdc.gov/healthyyouth /yrbs/pdf/us_suicide_trend_yrbs.pdf (accessed 2011 Oct. 27).

4. Brenner LA, Carlson NE, Harrison-Felix C, et al. Self-inflicted traumatic brain injury: characteristics and outcomes. Brain Inj 2009;23:991-8

5. Stensland MD, Zhu B, Ascher-Svanum H, et al. Costs associated with attempted suicide among individuals with bipolar disorder. J Ment Health Policy Econ 2010;13:87-92.

6. Johnston AK, Pirkis JE, Burgess PM. Suicidal thoughts and behaviours among Australian adults: findings from the 2007 National Survey of Mental Health and Wellbeing. Aust $N Z J$ Psychiatry 2009;43:635-43.

7. Shahid M, Khan MM, Naqvi H, et al. Cost of treatment of deliberate self-harm. A study from Pakistan. Crisis 2008;29:213-5.

8. O'Carroll PW, Potter LB.. Suicide contagion and the reporting of suicide: Recommendations from a national workshop. United States Department of Health and Human Services. MMWR Recomm Rep 1994;43:9-17.

9. Phillips DP. The influence of suggestion on suicide: substantive and theoretical implications of the Werther effect. Am Sociol Rev 1974;39:340-54.

10. Gould MS. Suicide and the media. Ann N Y Acad Sci 2001; 932:200-21, discussion 21-4.

11. Stack $S$. Suicide in the media: a quantitative review of studies based on non-fictional stories. Suicide Life Threat Behav 2005;35:121-33.

12. O'Carroll PW, Mercy JA. Responding to community-identified suicide clusters: statistical verification of the cluster is not the primary issue. Am J Epidemiol 1990;132(Suppl):S196-202. 
13. Gould MS, Wallenstein S, Kleinman MH, et al. Suicide clusters: an examination of age-specific effects. Am J Public Health 1990; 80:211-2.

14. Mercy JA, Kresnow MJ, O'Carroll PW, et al. Is suicide contagious? A study of the relation between exposure to the suicidal behavior of others and nearly lethal suicide attempts. Am J Epidemiol 2001; 154:120-7.

15. Robbins D, Conroy RC. A cluster of adolescent suicide attempts: Is suicide contagious? J Adolesc Health Care 1983;3:253-5.

16. Gould MS, Petrie K, Kleinman MH, et al. Clustering of attempted suicide: New Zealand national data. Int J Epidemiol 1994;23: 1185-9.

17. Joshi P, Damstrom-Albach D, Ross I, et al. Strengthening the safety net: a summary of the suicide prevention, intervention a postvention initative for $B C$. Vancouver (BC): The Suicide Prevention, Intervention and Postvention Intiative; 2009.

18. Niagara region suicide prevention strategy. St. Catherines (ON): Niagara Suicide Prevention Coalition; 2006.

19. American Foundation for Suicide Prevention and Suicide Prevention Resource Center. After a suicide: a toolkit for schools. Newton (MA): Education Development Center; 2011.

20. Suicide prevention (SUPRE). Geneva (Switzerland): World Health Organization; 2011. Available: www.who.int/mental _health/prevention/suicide/suicideprevent/en/index.html (accessed 2013 Feb. 1).

21. Human Resources and Skills Development Canada and Statistics Canada. Growing up in Canada: National Longitudinal Survey of Children and Youth. Ottawa (ON): Statistics Canada; 1996.

22. Human Resources and Skills Development Canada and Statistics Canada. National Longitudinal Survey of Children and Youth, cycle 8: user guide. Ottawa (ON): Statistics Canada; 2009.

23. Nock MK, Green JG, Hwang I, et al. Prevalence, correlates, and treatment of lifetime suicidal behavior among adolescents: results from the National Comorbidity Survey Replication Adolescent Supplement. JAMA Psychiatry 2013;70:300-10.

24. Boyle MH, Offord DR, Hofmann HG, et al. Ontario Child Health Study. I. Methodology. Arch Gen Psychiatry 1987;44:826-31.

25. Boyle MH, Offord DR, Racine Y, et al. Evaluation of the revised Ontario Child Health Study scales. J Child Psychol Psychiatry 1993;34:189-213

26. Boyle MH, Offord DR, Racine Y, et al. Evaluation of the original Ontario Child Health Study scales. Can J Psychiatry 1993;38: 397-405.

27. Merikangas KR, He JP, Burstein M, et al. Lifetime prevalence of mental disorders in US adolescents: results from the National Comorbidity Survey Replication - Adolescent Supplement (NCS-A). J Am Acad Child Adolesc Psychiatry 2010;49:980-9.

28. Cotton C. Recent developments in the low income cut offs. Ottawa (ON): Statistics Canada; 2001. Cat. no. 75F0002MIE2001003.

29. Cutrona CE. Social support in the transition to parenthood. J Abnorm Psychol 1984;93:378-90.

30. Cutrona CE, Russell D. The provisions of social relations and adaptation to stress. In: Jones WH, Perlman D, editors. Advances in personal relations. Greenwich (CT): JAI Press; 1987. p. 37-67.

31. Caron J. The scale of social provisions: their validation in Quebec [article in French]. Sante Ment Que 1996;21:158-80.
32. Williamson DE, Birmaher B, Ryan ND, et al. The stressful life events schedule for children and adolescents: development and validation. Psychiatry Res 2003;119:225-41.

33. Deaths and mortality rate, by selected grouped causes, age group and sex, Canada, annual. Ottawa (ON): Statistics Canada; 2013; Available: www5.statcan.gc.ca/cansim/ (accessed 2013 Feb. 1).

34. Brent DA, Moritz G, Bridge J, et al. Long-term impact of exposure to suicide: a three-year controlled follow-up. J Am Acad Child Adolesc Psychiatry 1996;35:646-53.

35. Roy A. Family history of suicide. Arch Gen Psychiatry 1983;40: 971-4.

36. Brent DA, Bridge J, Johnson BA, et al. Suicidal behavior runs in families. A controlled family study of adolescent suicide victims. Arch Gen Psych 1996;53:1145-52.

37. Hazell P, Lewin T. Friends of adolescent suicide attempters and completers. J Am Acad Child Adolesc Psychiatry 1993;32:76-81.

38. Brent DA, Perper J, Moritz G, et al. Psychiatric effects of exposure to suicide among the friends and acquaintances of adolescent suicide victims. J Am Acad Child Adolesc Psychiatry 1992; 31:629-39.

39. Brent DA, Perper J, Moritz G, et al. Adolescent witnesses to a peer suicide. J Am Acad Child Adolesc Psychiatry 1993;32: 1184-8.

Affiliations: From the Department of Epidemiology (Swanson), Harvard School of Public Health, Boston, Mass.; the Department of Epidemiology and Community Medicine (Colman), University of Ottawa, Ottawa, Ont.; and the School of Public Health (Colman), University of Alberta, Edmonton, Alta.

Contributors: Both authors conceived and designed the study and interpreted the results. Sonja Swanson performed the data analysis and wrote the manuscript. Both of the authors critically reviewed the manuscript and approved the final version submitted for publication.

Funding: This research was supported by a grant from the SickKids Foundation and the Canadian Institutes of Health Research (grant no. 116328). This research was undertaken, in part, thanks to funding from the Canada Research Chairs program for Ian Colman. The funders had no role in study design, data collection and analysis, decision to publish, or preparation of the manuscript.

Acknowledgements: The authors thank Ms. Irene Wong of Statistics Canada for her assistance with data access and use. The research and analysis are based on data from Statistics Canada and the opinions expressed do not represent the views of Statistics Canada. The authors also thank Kiyuri Naicker for her assistance with data analysis. Both authors had full access to all of the data in the study and take responsibility for the integrity of the data and the accuracy of the data analysis.

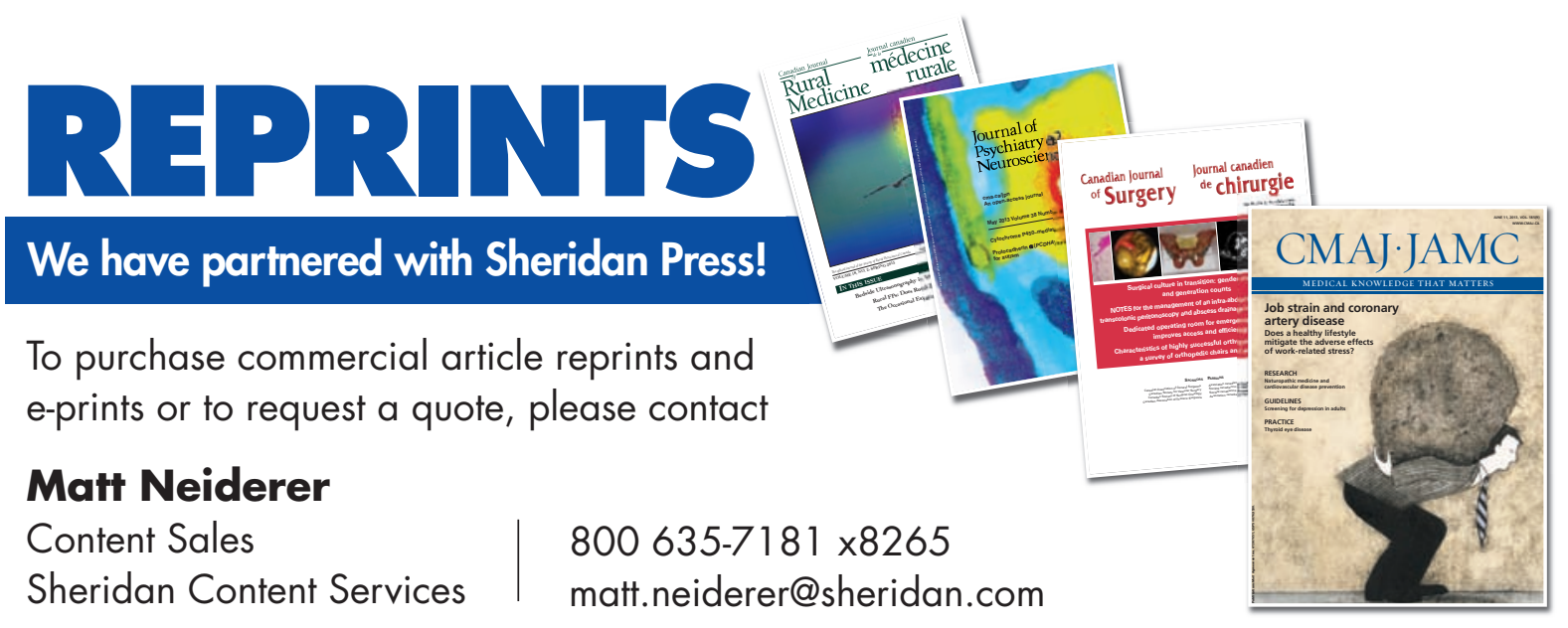

